\title{
Technical Note: An operational landslide early warning system at regional scale based on space-time-variable rainfall thresholds
}

\author{
S. Segoni, A. Battistini, G. Rossi, A. Rosi, D. Lagomarsino, F. Catani, S. Moretti, and N. Casagli \\ Department of Earth Sciences, University of Firenze, Florence, Italy \\ Correspondence to: S. Segoni (samuele.segoni@unifi.it)
}

Received: 1 October 2014 - Published in Nat. Hazards Earth Syst. Sci. Discuss.: 22 October 2014

Revised: 17 February 2015 - Accepted: 28 March 2015 - Published: 16 April 2015

\begin{abstract}
We set up an early warning system for rainfallinduced landslides in Tuscany $\left(23000 \mathrm{~km}^{2}\right)$. The system is based on a set of state-of-the-art intensity-duration rainfall thresholds (Segoni et al., 2014b) and makes use of LAMI (Limited Area Model Italy) rainfall forecasts and real-time rainfall data provided by an automated network of more than 300 rain gauges.

The system was implemented in a WebGIS to ease the operational use in civil protection procedures: it is simple and intuitive to consult, and it provides different outputs. When switching among different views, the system is able to focus both on monitoring of real-time data and on forecasting at different lead times up to $48 \mathrm{~h}$. Moreover, the system can switch between a basic data view where a synoptic scenario of the hazard can be shown all over the region and a more in-depth view were the rainfall path of rain gauges can be displayed and constantly compared with rainfall thresholds.

To better account for the variability of the geomorphological and meteorological settings encountered in Tuscany, the region is subdivided into 25 alert zones, each provided with a specific threshold. The warning system reflects this subdivision: using a network of more than 300 rain gauges, it allows for the monitoring of each alert zone separately so that warnings can be issued independently.

An important feature of the warning system is that the visualization of the thresholds in the WebGIS interface may vary in time depending on when the starting time of the rainfall event is set. The starting time of the rainfall event is considered as a variable by the early warning system: whenever new rainfall data are available, a recursive algorithm identifies the starting time for which the rainfall path is closest to or overcomes the threshold. This is considered the most
\end{abstract}

hazardous condition, and it is displayed by the WebGIS interface.

The early warning system is used to forecast and monitor the landslide hazard in the whole region, providing specific alert levels for 25 distinct alert zones. In addition, the system can be used to gather, analyze, display, explore, interpret and store rainfall data, thus representing a potential support to both decision makers and scientists.

\section{Introduction}

Landslide early warning systems (EWSs) are important tools for the scientific community, even if their potential is not yet fully exploited by society at large, including governments and decision makers (Baum and Godt, 2010; Intrieri et al., 2013; Glade and Nadim, 2014). In landslide-related hazards, many examples of site-specific EWSs have been reported (Michoud et al., 2013, and references therein), but when the area to be monitored is large (e.g., tens of thousands of squared kilometers - hereafter referred to as regional scale), EWSs are not so well established and the description of new case studies is needed.

At regional scale, warning systems for rainfall-induced landslides are mainly based on empirical rainfall thresholds (Keefer et al., 1987; Aleotti, 2004; Hong et al., 2005; Tiranti and Rabuffetti, 2010; Baum and Godt, 2010; Capparelli and Tiranti, 2010; Cannon et al., 2011; Floris et al., 2012; Jakob et al., 2012; Staley et al., 2013; Lagomarsino et al., 2013; Tiranti et al., 2014; Cucchi et al., 2015). A broad literature exists on empirical rainfall thresholds for the possible initiation of landslides (Guzzetti et al., 2007, and references therein), and intensity-duration $(I-D)$ thresholds are 
the most popular (Caine, 1980; Guzzetti et al., 2008; and references therein). However, some authors (e.g., Rosi et al., 2012) have highlighted that a comparison between rainfall paths and thresholds may produce different results depending on where the starting point of the rainfall event is set. Therefore, during the monitoring and forecasting activities, the starting point of the rainfall event can be considered as an additional variable, that in traditional studies on $I-D$ rainfall thresholds is not addressed or is solved with expert judgment, with the drawback that EWSs cannot consistently reproduce human choices. This issue is not present in EWSs based on rainfall parameters as measured over a given duration (Chleborad, 2003; Cardinali et al., 2006; Cannon et al., 2008, 2011; Martelloni et al., 2012; Zhuang et al., 2014).

In this work we describe the setting-up of a regional landslide EWS in Tuscany $\left(23000 \mathrm{~km}^{2}\right)$, Italy, and we discuss the main practical issues encountered.

The EWS is based on a set of recently published $I-D$ rainfall thresholds (Segoni et al., 2014b) that were defined using a recently proposed approach and methodology of analysis (Segoni et al., 2014a). The EWS combines LAMI (Limited Area Model Italy) weather forecasts and real-time rainfall measurements obtained by an automated network of 332 rain gauges. To account for the high spatial variability of the rainfall-landslide empirical relation, the hazard assessment is differentiated for each of the 25 alert zones. The EWS considers the starting time of the rainfall event as an additional variable and a recursive algorithm identifies the starting time associated with the highest hazard.

The EWS is implemented in a WebGIS system with advanced functions and an intuitive graphical interface. It provides a useful tool for assisting decision makers in assessing the warning level over the whole Tuscany region and at specific locations. The EWS and its WebGIS interface have been tested for 2 years with satisfactory results and are currently operated by the Tuscany Civil Protection Authority.

\section{Material and methods}

\subsection{Physical settings}

Tuscany $\left(23000 \mathrm{~km}^{2}\right)$ is an Italian region characterized by heterogeneous physical settings, including mountains up to an elevation of $2000 \mathrm{~m}$, coastal cliffs, plains and wide, hilly areas (Fig. 1).

The main reliefs are distributed in the northern and eastern parts of the region, and they belong to the Northern Apennines, a NW-NE-elongated orogenic belt that formed subsequent to the Upper Cretaceous by the stacking of Ligurian units over Tuscan-Umbrian units and over metamorphic Tuscan units by the intercalation of sub-Ligurian units (Bortolotti, 1992; Vai and Martini, 2001). Apennines flysch ridges are alternated with intermontane basins, which are basically grabens or semi-grabens filled with lacustrine and flu-

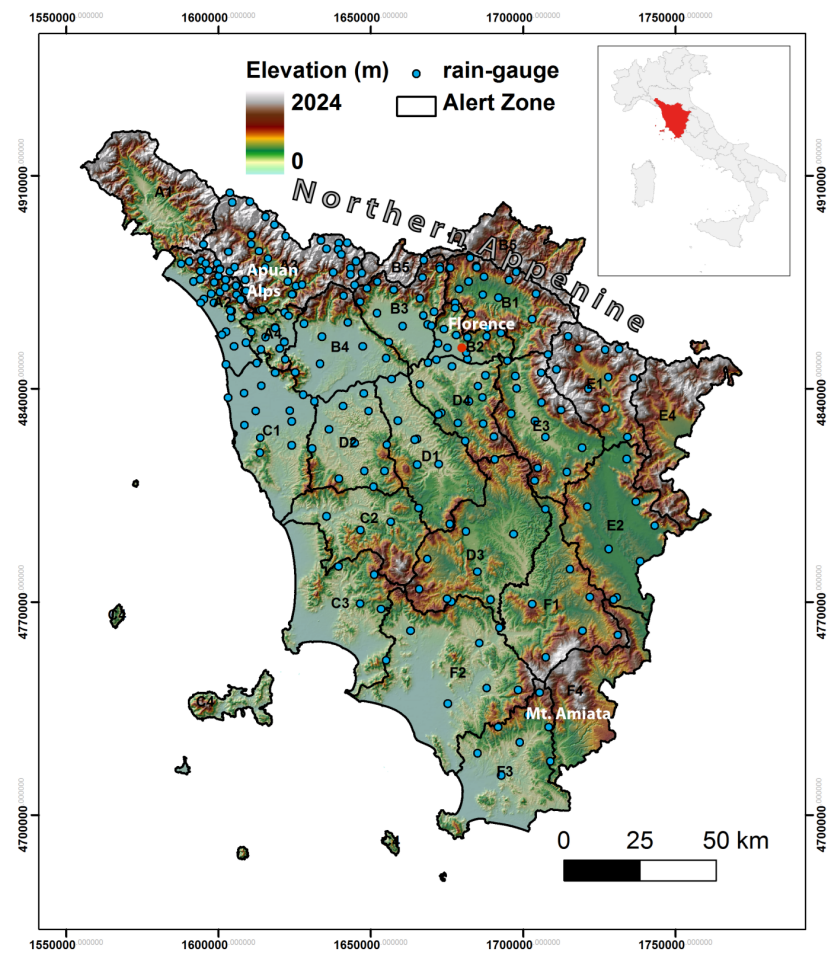

Figure 1. Study area (Tuscany, central Italy).

vial granular and cohesive deposits. Other main reliefs are made up of metamorphic rocks, to the northwest, and volcanic rocks, to the south. The hills that characterize a large part of the Tuscan landscape consist of cohesive or granular deposits.

Landslide processes have pervasively shaped the Tuscan landscape and are still an active geomorphic process in the whole region. Tuscany is affected by different landslide typologies, depending on bedrock lithology and landscape morphology. For instance, shallow landslides prevail in the northern steep mountainsides made up of flysch or schist rocks, while the hills made up of regolith, soils or soft rocks are mainly characterized by reactivations of rotational slides.

The Tuscan rainfall regime is typically Mediterranean: the main peak of precipitation is in autumn, and summer is the driest season. The rainfall amount varies largely depending on the main reliefs. The maximum values of mean annual precipitation (about $2000 \mathrm{~mm}_{\text {year }}{ }^{-1}$ ) are found in the northwest and are favored by high mountains located near the warm Mediterranean Sea. The minimum values of mean annual precipitation are found in the southern plains and are lower than $600 \mathrm{~mm}$ year $^{-1}$ (Rosi et al., 2012).

\subsection{State-of-the-art rainfall thresholds}

The different physical settings that are present in Tuscany correspond to different empirical relationships between rainfall and landslides. Segoni et al. (2014b) demonstrated that 
Table 1. Threshold equation and no rain gap values used in the early warning system for each alert zone (modified after Segoni et al., 2014b).

\begin{tabular}{|c|c|c|}
\hline Alert zone & Threshold & No rain gap (hours) \\
\hline A1 & $I=61.4 D^{-0.78}$ & 18 \\
\hline $\mathrm{A} 2$ & $I=34.0 D^{-0.86}$ & 18 \\
\hline A3 & $I=52.4 D^{-0.73}$ & 24 \\
\hline A4 & $I=101.5 D^{-0.99}$ & 18 \\
\hline B1 & $I=33.8 D^{-0.81}$ & 20 \\
\hline B2 & $I=22.5 D^{-0.65}$ & 24 \\
\hline B3 & $I=22.5 D^{-0.65}$ & 24 \\
\hline B4 & $I=49.9 D^{-0.73}$ & 24 \\
\hline B5 & $I=405.9 D^{-1.29}$ & 24 \\
\hline $\mathrm{C} 1$ & $I=49.2 D^{-0.77}$ & 24 \\
\hline $\mathrm{C} 2$ & $I=49.2 D^{-0.77}$ & 24 \\
\hline $\mathrm{C} 3$ & $I=49.2 D^{-0.77}$ & 24 \\
\hline $\mathrm{C} 4$ & $I=49.2 D^{-0.77}$ & 24 \\
\hline D1 & $I=40.5 D^{-0.90}$ & 24 \\
\hline D2 & $I=31.6 D^{-0.76}$ & 12 \\
\hline D3 & $I=40.5 D^{-0.90}$ & 24 \\
\hline D4 & $I=33.5 D^{-0.74}$ & 15 \\
\hline E1 & $I=20.0 D^{-0.66}$ & 12 \\
\hline E2 & $I=29.6 D^{-0.75}$ & 12 \\
\hline E3 & $I=20.9 D^{-0.78}$ & 10 \\
\hline E4 & $I=15.0 D^{-0.69}$ & 32 \\
\hline $\mathrm{F} 1$ & $I=37.2 D^{-0.88}$ & 24 \\
\hline $\mathrm{F} 2$ & $I=50.7 D^{-0.78}$ & 36 \\
\hline F3 & $I=50.7 D^{-0.78}$ & 36 \\
\hline F4 & $I=37.2 D^{-0.88}$ & 24 \\
\hline
\end{tabular}

the effectiveness of the warning system could be enhanced by subdividing the region into 25 independent alert zones (AZs) (Fig. 1), each one characterized by a prevailing landslide typology and by a specific $I-D$ rainfall threshold. Following this approach, in the warning system we implemented the set of $I-D$ thresholds proposed by Segoni et al. (2014b) and reported in Table 1.

The thresholds are defined considering a power-law function in the form (Caine, 1980)

$I=a D^{-b}$,

where $I\left(\mathrm{~mm} \mathrm{~h}^{-1}\right)$ and $D(\mathrm{~h})$ are rainfall intensity and duration, respectively, and $a$ and $b$ are empirical parameters.

A complete insight into the methodology used to define the threshold can be found in Segoni et al. (2014a). Hereafter, we summarize two original features of the threshold analysis performed by Segoni et al. (2014a), as they influenced the setting-up of the EWS.

First, each threshold is characterized by an additional parameter, namely the "no rain gap" (NRG), which represents the amount of time without rainfall that is needed to consider two consecutive rainfall events as separate.

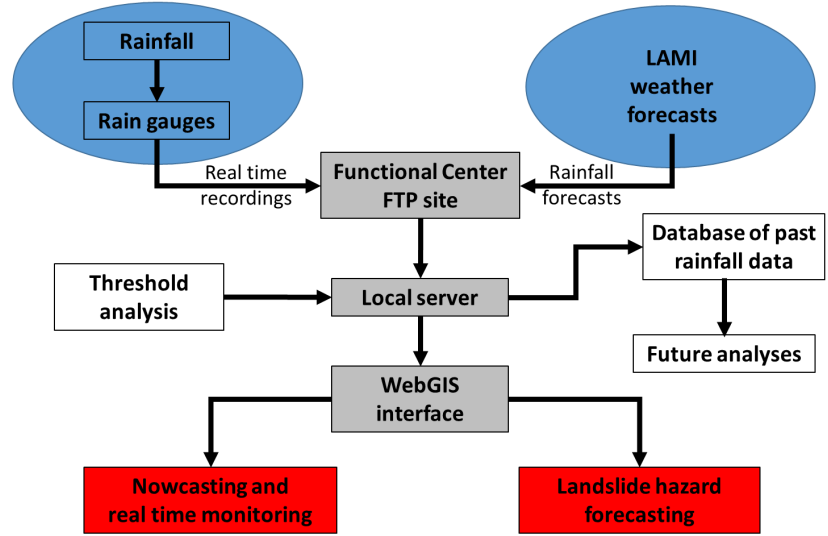

Figure 2. Architecture of the early warning system.

Second, since the main goal is to warn of landslides triggered by extraordinary rainfall events, the thresholds are defined and calibrated by a relationship between recent landslides and the most severe rainfall conditions measured in their vicinity (Segoni et al., 2014a). The severity of rainfall is estimated by means of its return period, which can be calculated combining both intensity and duration (Segoni et al., 2014a). The methodology also accounts for the possibility that complex rainfall events may be characterized by a series of peaks of short duration and great intensity (hereafter referred to as sub-events) alternated with periods of mild intensity or no rain shorter than NRG. One of these sub-events may be associated with a higher return period: in such a case, its $I-D$ values are used in threshold analysis instead of those of the entire rainfall event.

These two peculiar features may be useful to standardize and automate the rainfall analysis, but they need to be consistently replicated in the EWS to ensure a conceptual continuity from the theoretical analysis and the actual operational use of the thresholds.

\subsection{Architecture of the early warning system}

The architecture of the warning system is summarized in Fig. 2.

The Tuscany region has an automated network consisting of 332 rain gauges. Most of these instruments measure rainfall at hourly time steps, and each measure is sent in real time to the Tuscany Region Functional Center, which is in charge of maintaining the network and collecting and storing all the measured data on a secure FTP (File Transfer Protocol) server. Rainfall data are stored in a comma-separated value (CSV) file containing, for each rain gauge, the hourly rainfall intensity measured in millimeters per hour. The file is constantly updated. The FTP server hosts and constantly updates another CSV file containing information such as name, geographical coordinates and elevation of each active rain gauge belonging to the network. 

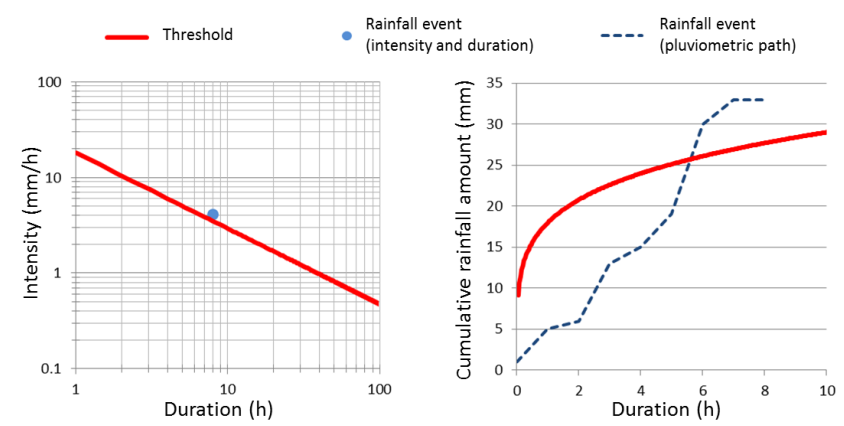

Figure 3. Left panel: a typical $\log -\log I-D$ plot that allows for comparison of a power-law threshold and a rainfall event expressed in terms of its intensity and duration. Right panel: the same threshold and the same rainfall event are expressed in terms of duration and cumulative rainfall amount, allowing for constant monitoring of the evolution of the rainfall path with respect to the warning threshold.

A real-time warning system service is implemented using PHP scripting (http://www.php.net/): every $15 \mathrm{~min}$ the script establishes a connection to the FTP site, checks for the presence of updated CSV files, downloads them and stores the data in a local DBMS (database management system). According to Shannon theory (Shannon, 1948), the connection frequency should be at least double the frequency of rain gauge measurements: this allows for a quick recovery in the case of delays in data transmission and enhances the resilience of the system.

The local DBMS is a MySQL database (http://www. mysql.com) where the information provided by the CSV file is replicated. The database also contains some keys to create a bidirectional relationship between alert zones and rain gauges. In addition, a table stores, for each alert zone, all the parameters needed to define the threshold equation $(\alpha$ and $\beta$ ) and to allow for a correct interpretation of the rainfall paths (no rain gap).

Immediately after each update, the rainfall paths are updated and the new values of cumulative rainfall recorded by each rain gauge are compared with the threshold of the alert zone.

An alert is raised in a given alert zone if at least one of its rain gauges exceeds the threshold. This approach, thanks to the high number of active rain gauges in each alert zone, enhances the resilience of the system to malfunctions and delays in data transmission, which may be experienced during severe storms.

Even if rainfall thresholds are expressed in terms of intensity $\left(\mathrm{mm} \mathrm{h}^{-1}\right)$ and duration (h), the warning system software interface operates in terms of rainfall amount $(\mathrm{mm})$ and duration (h) in order to ease the interpretation of the time evolution of the rainfall event by the civil protection personnel (Fig. 3). The conversion from rainfall intensity $(I)$ to rainfall amount $(C)$ is obtained by considering that $C=I D$.

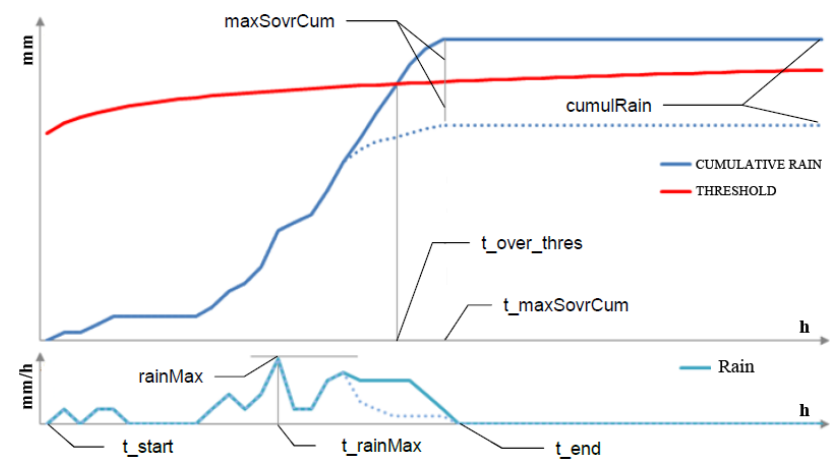

Figure 4. Parameters used to characterize each rainfall event stored in the database: $t$ _start and $t$ _end is the time when the rainfall event starts and ends, respectively; cumulRain is the final value of cumulative rainfall $(\mathrm{mm})$; maxSovrCum is the maximum value exceeding the threshold (or minimum distance from the threshold when not exceeded) (mm); $t$ maxSovrCum is the time of occurrence of maxSovrCum; t_over_thres is the time when the threshold was first exceeded; rainMax is the maximum rainfall intensity $\left(\mathrm{mm} \mathrm{h}^{-1}\right)$; and t_rainMax is the time of occurrence of rainMax. To show all the possible cases, two examples of rainfall events are represented: the dotted line refers to a rainfall event that does not exceed the thresholds, while the solid line represents a rainfall event that exceeds the thresholds.

In this way, the generic form of the rainfall threshold formula (Eq. 1) can be rewritten as

$C=D a D^{-b}=a D^{1-b}$.

In this form, the thresholds can be displayed in a simple plot and directly compared to the rainfall path recorded by the rain gauge to immediately show the cumulated rainfall and the additional amount needed to exceeded the threshold (Fig. 3).

The rainfall event is considered to be finished after a norain period equal to or larger than the NRG has elapsed. A new rainfall path will be built and analyzed independently starting from the next recorded precipitation. The data in the database are deleted to reduce the amount of resources used, but the system stores a steady stream of rain information on DB and CSV files. Rainfall events with cumulative values greater than $20 \mathrm{~mm}$ are characterized by a set of parameters (Fig. 4) which are stored as well for future reference:

- ID_rg: unique ID of the rain gauge (used as a link to other data);

- $t \_s t a r t:$ time when the rainfall event starts;

- $\mathrm{t} \_$end: time when the rainfall event ends;

- status: alert issued or not;

- cumulRain: final value of cumulative rainfall (mm); 


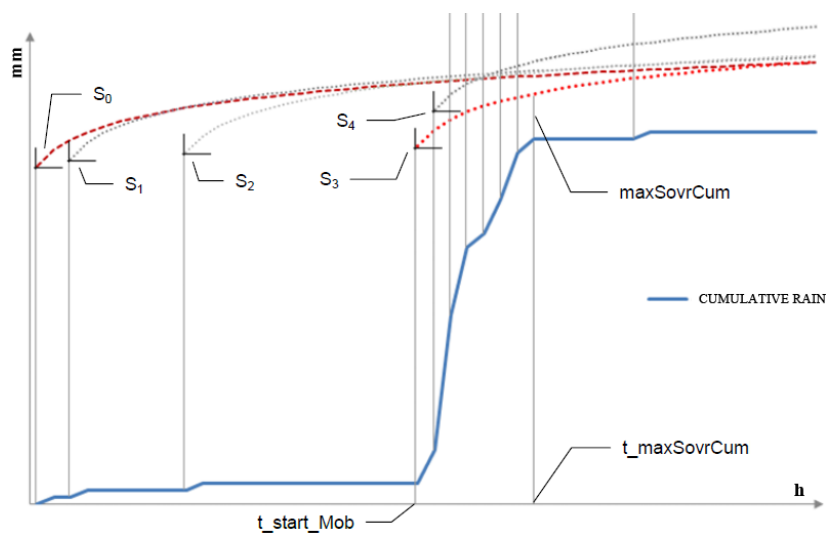

Figure 5. Example of the functioning of the algorithm that shifts the initial time of the rainfall until the highest hazard is identified: $\mathrm{S} 1$ to $\mathrm{S} 4$ are four examples of shifted starting time; maxSovrCum is the maximum value exceeding the threshold (or minimum distance from the threshold when not exceeded) (mm); t_maxSovrCum is the time of occurrence of maxSovrCum; and t_start_Mob is the starting time to be considered to obtain the highest value of maxSovrCum.

- maxSovrCum: maximum value exceeding the threshold (or minimum distance from the threshold when not exceeded) (mm);

- t_maxSovrCum: time of occurrence of maxSovrCum;

- t_over_thres: time when the threshold was first exceeded;

- rainMax: maximum rainfall intensity $\left(\mathrm{mm} \mathrm{h}^{-1}\right)$;

- t_rainMax: time of occurrence of rainMax.

As we have seen, in some cases the whole rainfall event "t_start-t_end" does not represent the most hazardous condition. This is the case, for example, in complex rain paths where very intense rain bursts are alternated, over long durations, with less intense episodes. This possibility is taken into account by the methodology used for the threshold definition (Segoni et al., 2014a, and Sect. 2.2), and a consistent approach is needed for the EWS as well.

We therefore implemented a recursive procedure in which a script computes all the possible cumulative rainfall paths starting between t_start and the current time. Then, all the cumulative curves are compared with the threshold to calculate the maxSovrCum values. The warning system takes into account the highest maxSovrCum value, which is assumed to be the most hazardous condition. This procedure is depicted in Fig. 5 and consists in shifting the beginning of the rainfall event until the highest value of maxSovrCum is found. In other words, the combination that exceeds the threshold by the largest amount (or that is below it by the shortest distance) is selected and shown in the WebGIS interface introduced in the following section of the manuscript.
The system, as described so far, allows for nowcasting and monitoring activities. In addition, the EWS has forecasting capabilities because it can incorporate the rainfall forecasts into the rainfall path as well.

According to the regional laws and the civil protection procedures, the Tuscany Region Functional Center is in charge of providing rainfall forecasts, with $6,12,24$ and $48 \mathrm{~h}$ lead times, which are estimated using the LAMI meteorological model (Cacciamani et al., 2002). LAMI forecasts are commonly used in hydrological and hydrogeological modeling (Taramasso et al., 2005).

Since LAMI data are spatially distributed (with a horizontal resolution of $7 \mathrm{~km}$ ), they are automatically sampled at each pluviometer location. These values are saved in a CSV file stored on the FTP server. When the connection to the FTP server is established, a script transfers these values to the warning system. For each gauge station, local rainfall forecast values are summed to the real-time measurements and the cumulative rainfall amount is estimated for four different future scenarios $(6,12,24$ and $48 \mathrm{~h}$ in advance). With the help of a purposely developed WebGIS interface (see next section), it is therefore possible to assess whether the threshold will be exceeded or not with a suitable lead time so as to ensure an effective early warning capability.

\subsection{WebGIS interface}

A WebGIS was developed with the purpose of providing the civil protection personnel with a straightforward tool for both the forecasting and the real-time monitoring of the temporal evolution of the hazard level associated with rainfall-induced landslides.

The WebGIS continuously connects to the database $(60 \mathrm{~s}$ refresh time) and, in its basic view, displays the status of all the rain gauges of the network using different colors depending on the value of cumulative rainfall (Fig. 6). The possible states of the system are

- inactive (no data available because of malfunctioning or temporary communication breakdown);

- no rain (no rain recorded in the last $X$ hours, where $X$ represents the no rain gap of the alert zone);

- ordinary (rainfall below the threshold);

- alert (rainfall above the threshold).

If needed, the WebGIS allows for a more in-depth control on rain gauges. With a hyper-textual link, each rain gauge can be accessed and its rainfall path is displayed and compared with the threshold (Fig. 6). The system allows the operator to consider both the real-time scenario, e.g., for monitoring purposes (Fig. 6), and the forecasted scenario at different lead times (in this case rainfall forecasts are coupled with the real-time measurements) (Fig. 7). In the background, an algorithm shifts the initial time of the rainfall until the worst 


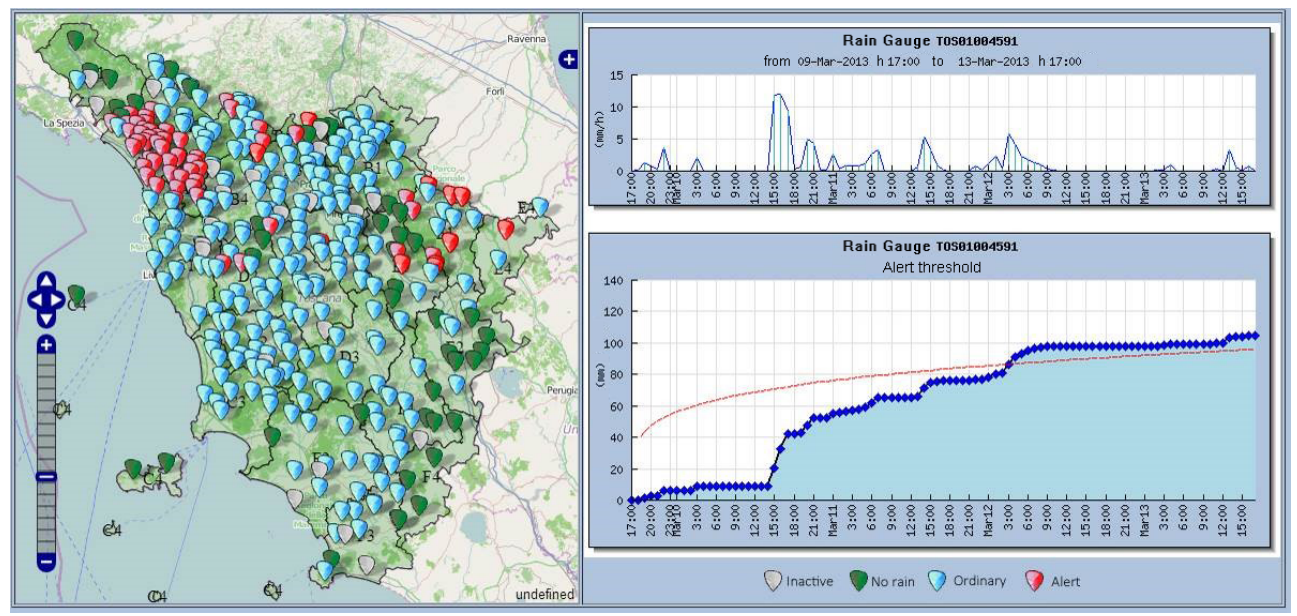

Figure 6. WebGIS interface of the warning system. An overview of the regional rain-gauge network is provided on the left, while on the right, for each rain gauge, the rainfall path can be displayed and compared to the threshold.

scenario (in terms of maxSovrCum) is identified and shown in the WebGIS (Fig. 7).

\section{Results and discussion}

The system went through a two-year test phase with a continuous feedback from the civil protection personnel that allowed the optimization of the visual interface to the operational needs experienced during the management of emergency phases. The EWS has now been integrated into the official civil protection procedures.

According to Stähli et al. (2014), one of the main challenges in EWS implementation is to make the system comprehensible and usable by operators. Based on the feedback received during the main critical events, the comprehensibility and the performance of the system have been evaluated positively by the Tuscany Civil Protection Authority.

For example, Fig. 8 shows the specific case of the December 2013 rainfall event that struck northwest Tuscany. According to official civil protection reports, the event triggered an unspecified number of landslides in alert zone A3, and two rain gauges just exceeded the alert threshold. In addition to the spatial accuracy, in this case the timing of the alert was in good agreement with the ground truth as well: according to reports, all landslides occurred between 28 and 29 December, and this is approximately the time when the threshold was exceeded.

Figure 6 shows another successful case study: the March 2013 event was characterized by a very prolonged low-intensity rainfall, almost without high-intensity peaks. Such a circumstance is usually unfavorable to $I-D$ thresholds, which are considered to be particularly appropriate for short and intense rainfalls. Nonetheless, the warning system outputs were in accordance with the official civil protection reports. We believe that this result could be partially due to the use of space-variable no rain gaps, which in some circumstances can be very long (up to $36 \mathrm{~h}$, as reported by Segoni et al., 2014b), thus allowing for the rainfalls with low intensity and long duration to be properly accounted for.

Even though the civil protection procedure consists of issuing a warning if a single pluviometer exceeds the threshold, the possibility of closer inspection and investigation of the behavior of a dense rain-gauge network may allow for the identification of areas where the rainfall is particularly severe and the most relevant effects to the ground (landsliding) could be expected, in a spatially distributed way. To improve this capability, an ongoing research project is experimenting with the coupling of EWSs based on rainfall thresholds with landslide susceptibility maps (Catani et al., 2013; Segoni et al., 2014c) and with physically based slope stability models (Mercogliano et al., 2013; Rossi et al., 2013).

Another future improvement will regard the quantification of the uncertainty associated with the threshold parameters, which has been introduced for the first time in threshold analyses by Peruccacci et al. (2012) and has not yet been assessed for the threshold used in the EWS.

It is important to stress that constant updating and maintenance activity is scheduled for the warning system. In particular, as soon as new rainfall events produce relevant landslide impacts, the civil protection agency produces electronic records that can be easily added to the existing landslide geodatabase. As soon as the landslide population increases significantly, the WebGIS interface of the EWS can be used to extract the relative rainfall data and to update the thresholds if needed. Constant updating activity is necessary, as recent studies have demonstrated that an increased landslide sample may lead to an improvement in the performances of the warning system (Lagomarsino et al., 2013; Gariano et al., 2015; Rosi et al., 2015) and to a reduction in the uncertainties as- 


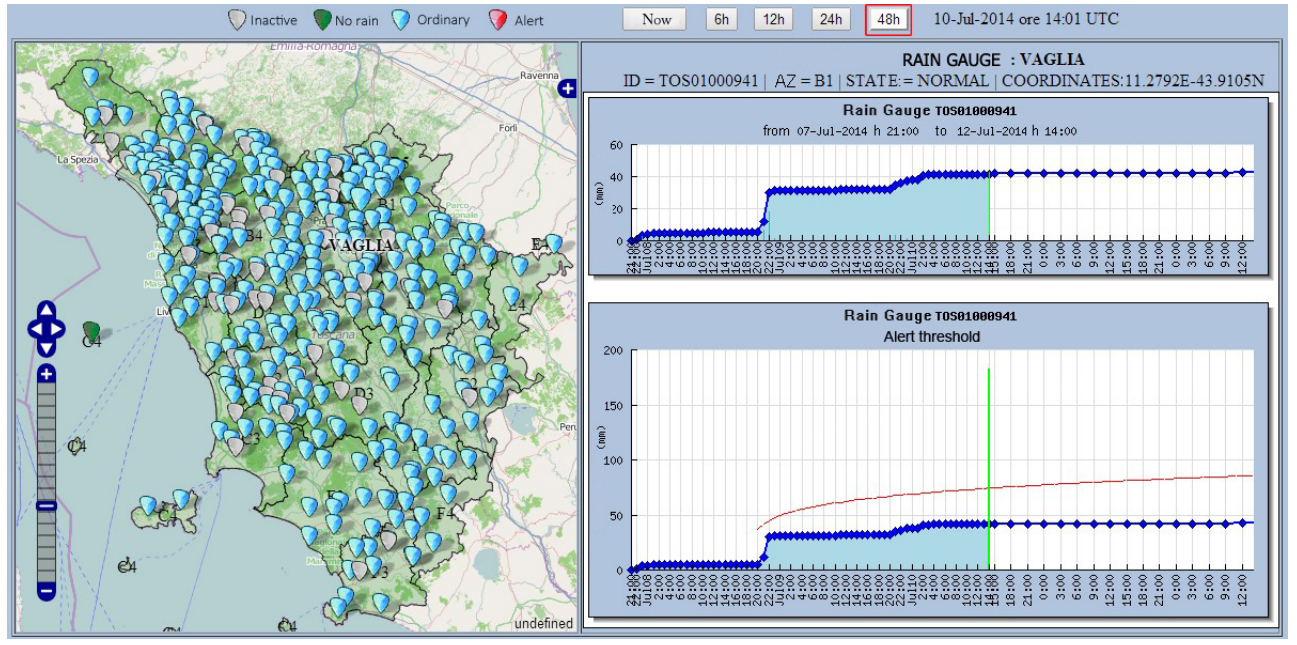

Figure 7. WebGIS interface in the forecasting mode ( $48 \mathrm{~h}$ lead time). The green line represents the current time and separates real-time data (left) and rainfall forecasts (right); please note that in this case the highest level of hazard is obtained considering a t_start other than the beginning of the rainfall event.

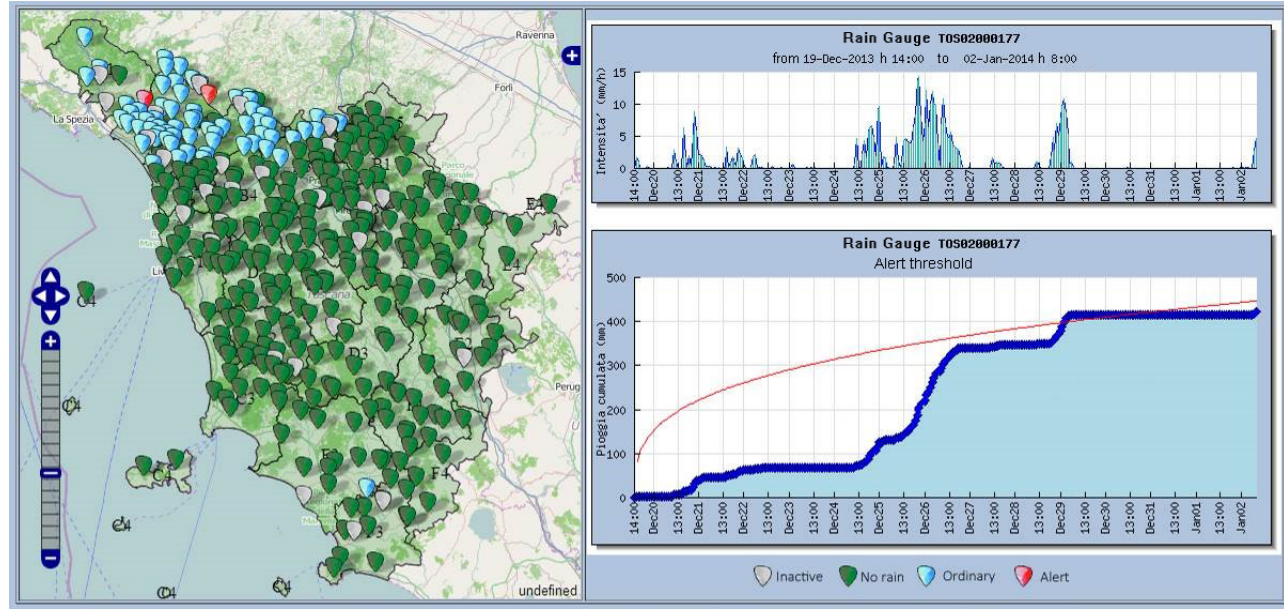

Figure 8. Evolution of the rainfall event that struck in northern Tuscany on December 2013.

sociated with the threshold parameter estimation (Peruccacci et al., 2012; Vennari et al., 2014).

\section{Conclusions}

We set up an early warning and monitoring system for rainfall-induced landslides in Tuscany $\left(23000 \mathrm{~km}^{2}\right)$. The system is based on a set of $I-D$ rainfall thresholds and makes use of LAMI rainfall forecasts and real-time rainfall data supplied by an automated network of more than 300 rain gauges.

The EWS was implemented in a WebGIS to ease the operational use in civil protection procedures: it is intuitive and simple to consult, and it provides different outputs. When switching among different views, the system is able to focus both on monitoring of real-time data and on forecasting haz- ards at different lead times. Moreover, the system can switch between a very straightforward view where a synoptic scenario of the hazard can be shown all over the study area and a more in-depth view where the rainfall path of rain gauges can be displayed and constantly compared with rainfall thresholds.

One of the main peculiar features of the warning system is the use of space-time-variable thresholds, which overcome two issues commonly encountered when passing from the definition of $I-D$ thresholds to their actual implementation in EWSs for civil protection purposes. The first issue is timerelated: depending on when the starting point of the critical rainfall event is set, the comparison between rainfall path and threshold may produce different results. In our approach this temporal variability is taken into account by a script that recursively considers all possible starting points and selects the 
most unfavorable condition for the EWS. The second issue is space-related: to better account for the high variability in the physical features encountered in the test site, we used a mosaic of local thresholds rather than a single regional rainfall threshold.

After a 2-year test period, the EWS is now operated by the Tuscany Civil Protection Authority and used for hazards related to landslides of all typologies.

Acknowledgements. This work was carried out in collaboration with the Tuscany Civil Protection Authority and the National Civil Protection Department. We express our gratitude to the Tuscany Civil Protection Authority and the Tuscany Region Functional Center for providing the data for the analysis and for the constant support.

Edited by: F. Guzzetti

Reviewed by: two anonymous referees

\section{References}

Aleotti, P.: A warning system for rainfall-induced shallow failures, Eng. Geol., 73, 247-265, 2004.

Baum, R. L. and Godt, J. W.: Early warning of rainfall-induced shallow landslides and debris flows in the USA, Landslides, 7, 259272, 2010.

Bortolotti, V.: The Tuscany-Emilian Apennine, Regional Geological Guidebook, Vol. 4, S.G.I., BEMA Editrice, Milan, 1992 (in Italian).

Cacciamani, E. P., Ferri, M., and Minguzzi, E.: High resolution verification of hydrostatic and non-hydorstatic LAM precipitation forecasts in Italy, in: COSMO newsletter, edited by: Doms, G. and Shatter, U., Vol. II, Offenbach, Germany, 176-186, 2002.

Caine, N.: The rainfall intensity-duration control of shallow landslides and debris flows, Geogr. Ann., 62, 23-27, 1980.

Cannon, S., Boldt, E., Laber, J., Kean, J., and Staley, D.: Rainfall intensity-duration thresholds for postfire debris-flow emergencyresponse planning, Nat. Hazards, 59, 209-236, 2011.

Cannon, S. H., Gartner, J. E., Wilson, R., Bowers, J., and Laber, J.: Storm rainfall conditions for floods and debris flows from recently burned areas in southwestern Colorado and southern California, Geomorphology, 96, 250-269, 2008.

Capparelli, G. and Tiranti, D.: Application of the MoniFLaIR early warning system for rainfall-induced landslides in Piedmont region (Italy), Landslides, 7, 401-410, 2010

Cardinali, M., Galli, M., Guzzetti, F., Ardizzone, F., Reichenbach, P., and Bartoccini, P.: Rainfall induced landslides in December 2004 in south-western Umbria, central Italy: types, extent, damage and risk assessment, Nat. Hazards Earth Syst. Sci., 6, 237260, doi:10.5194/nhess-6-237-2006, 2006.

Catani, F., Lagomarsino, D., Segoni, S., and Tofani, V.: Landslide susceptibility estimation by random forests technique: sensitivity and scaling issues, Nat. Hazards Earth Syst. Sci., 13, 2815-2831, doi:10.5194/nhess-13-2815-2013, 2013.

Chleborad, A. F.: Preliminary evaluation of a precipitation threshold for anticipating the occurrence of landslides in the Seattle,
Washington Area, US Geological Survey Open-File Report 03, 463 pp., 2003.

Cucchi, A., Valsecchi, I. Q., Alberti, M., Fassi, P., Molari, M., and Mannucci, G.: The alerting system for hydrogeological hazard in Lombardy Region, northern Italy: rainfall thresholds triggering debris-flows and "equivalent rainfall" method, Nat. Hazards Earth Syst. Sci. Discuss., 3, 269-290, doi:10.5194/nhessd-3-2692015, 2015.

Floris, M., D’Alpaos, A., De Agostini, A., Stevan, G., Tessari, G., and Genevois, R.: A process-based model for the definition of hydrological alert systems in landslide risk mitigation, Nat. Hazards Earth Syst. Sci., 12, 3343-3357, doi:10.5194/nhess-123343-2012, 2012.

Gariano, S. L., Brunetti, M. T., Iovine, G., Melillo, M., Peruccacci, S., Terranova, O., Vennari, C., and Guzzetti, F.: Calibration and validation of rainfall thresholds for shallow landslide forecasting in Sicily, southern Italy, Geomorphology, 228, 653-665, 2015.

Glade, T. and Nadim, F.: Early warning systems for natural hazards and risks, Nat. Hazards, 70, 1669-1671, 2014.

Guzzetti, F., Peruccaci, S., Rossi, M., and Stark, C. P.: Rainfall thresholds for the initiation of landslides in central and southern Europe, Meteorol. Atmos. Phys., 98, 239-267, 2007.

Guzzetti, F., Peruccacci, S., Rossi, M., and Stark, C. P.: The rainfall intensity-duration control of shallow landslides and debris flows: An update, Landslides, 5, 3-17, 2008.

Hong, Y., Hiura, H., Shino, K., Sassa, K., Suemine, A., Fukuoka, H., and Wang, G.: The influence of intense rainfall on the activity of large-scale crystalline schist landslides in Shikoku Island, Japan, Landslides, 2, 97-105, 2005.

Intrieri, E., Gigli, G., Casagli, N., and Nadim, F.: Brief communication "Landslide Early Warning System: toolbox and general concepts", Nat. Hazards Earth Syst. Sci., 13, 85-90, doi:10.5194/nhess-13-85-2013, 2013.

Jakob, M., Owen, T., and Simpson, T.: A regional real-time debris-flow warning system for the District of North Vancouver, Canada, Landslides, 9, 165-178, 2012.

Keefer, D. K., Wilson, R. C., Mark, R. K., Brabb, E. E., Brown III, W. M., Ellen, S. D., Harp, E. L., Wieczoreck, G. F. Alger, C. S., and Zatkin, R. S.: Real-time landslide warning during heavy rainfall, Science, 238, 921-926, 1987.

Lagomarsino, D., Segoni, S., Fanti, R., and Catani, F.: Updating and tuning a regional-scale landslide early warning system, Landslides, 10, 91-97, 2013.

Martelloni, G., Segoni, S., Fanti, R., and Catani, F.: Rainfall thresholds for the forecasting of landslide occurrence at regional scale, Landslides, 9, 485-495, 2012.

Mercogliano, P., Segoni, S., Rossi, G., Sikorsky, B., Tofani, V., Schiano, P., Catani, F., and Casagli, N.: Brief communication "A prototype forecasting chain for rainfall induced shallow landslides", Nat. Hazards Earth Syst. Sci., 13, 771-777, doi:10.5194/nhess-13-771-2013, 2013.

Michoud, C., Bazin, S., Blikra, L. H., Derron, M.-H., and Jaboyedoff, M.: Experiences from site-specific landslide early warning systems, Nat. Hazards Earth Syst. Sci., 13, 2659-2673, doi:10.5194/nhess-13-2659-2013, 2013.

Peruccacci, S., Brunetti, M. T., Luciani, S., Vennari, C., and Guzzetti, F.: Lithological and seasonal control on rainfall thresholds for the possible initiation of landslides in Central Italy, Geomorphology, 139-140, 79-90, 2012. 
Rosi, A., Lagomarsino, D., Rossi, G., Segoni, A., Battistini, A., and Casagli, N.: Updating EWS rainfall thresholds for the triggering of landslides, Nat. Hazards, doi:10.1007/s11069-015-1717-7, in press, 2015.

Rosi, A., Segoni, S., Catani, F., and Casagli, N.: Statistical and environmental analyses for the definition of a regional rainfall threshold system for landslide triggering in Tuscany (Italy), J. Geogr. Sci., 22, 617-629, 2012.

Rossi, G., Catani, F., Leoni, L., Segoni, S., and Tofani, V.: HIRESSS: a physically based slope stability simulator for HPC applications, Nat. Hazards Earth Syst. Sci., 13, 151-166, doi:10.5194/nhess-13-151-2013, 2013.

Shannon, C. E.: A mathematical theory of communication, Bell Syst. Tech. J., 27, 379-423, 1948.

Segoni, S., Rossi, G., Rosi, A., and Catani, F.: Landslides triggered by rainfall: a semiautomated procedure to define consistent intensity-duration thresholds, Comput. Geosci., 3063, 123-131, 2014a.

Segoni, S., Rosi, A., Rossi, G., Catani, F., and Casagli, N.: Analysing the relationship between rainfalls and landslides to define a mosaic of triggering thresholds for regional-scale warning systems, Nat. Hazards Earth Syst. Sci., 14, 2637-2648, doi:10.5194/nhess-14-2637-2014, 2014b.

Segoni, S., Lagomarsino, D., Fanti, R., Moretti, S., and Casagli, N.: Integration of rainfall thresholds and susceptibility maps in the Emilia Romagna (Italy) regional-scale landslide warning system, Landslides, doi:10.1007/s10346-014-0502-0, in press, 2014c.

Stähli, M., Sättele, M., Huggel, C., McArdell, B. W., Lehmann, P., Van Herwijnen, A., Berne, A., Schleiss, M., Ferrari, A., Kos, A., Or, D., and Springman, S. M.: Monitoring and prediction in Early Warning Systems (EWS) for rapid mass movements, Nat. Hazards Earth Syst. Sci. Discuss., 2, 7149-7179, doi:10.5194/nhessd-2-7149-2014, 2014.
Staley, D. M., Kean, J. W., Cannon, S. H., Schmidt, K. M., and Laber, J. L.: Objective definition of rainfall intensity-duration thresholds for the initiation of post-fire debris flows in southern California, Landslides, 10, 547-562, doi:10.1007/s10346-0120341-9, 2013.

Taramasso, A. C., Gabellani, S., and Parodi, A.: An operational flash-flood forecasting chain applied to the test cases of the EU project HYDROPTIMET, Nat. Hazards Earth Syst. Sci., 5, 703710, doi:10.5194/nhess-5-703-2005, 2005.

Tiranti, D., Cremonini, R., Marco, F., Gaeta, A. R., and Barbero, S.: The DEFENSE (debris Flows triggEred by storms - nowcasting system): An early warning system for torrential processes by radar storm tracking using a Geographic Information System (GIS), Comput. Geosci., 70, 96-109, 2014

Tiranti, D. and Rabuffetti, D.: Estimation of rainfall thresholds triggering shallow landslides for an operational warning system implementation, Landslides, 7, 471-481, 2010.

Vai, G. B. and Martini, I. P.: Anatomy of an Orogen: The Appennines and adjacent Mediterranean Basins, Dortdrecht/Boston/London, Kluver Academic Publishers, 2001.

Vennari, C., Gariano, S. L., Antronico, L., Brunetti, M. T., Iovine, G., Peruccacci, S., Terranova, O., and Guzzetti, F.: Rainfall thresholds for shallow landslide occurrence in Calabria, southern Italy, Nat. Hazards Earth Syst. Sci., 14, 317-330, doi:10.5194/nhess-14-317-2014, 2014.

Zhuang, J. Q., Iqbal, J., Peng, J. B., and Liu, T. M.: Probability prediction model for landslide occurrences in Xi' an, Shaanxi Province, China, J. Mountain Sci., 11, 345-359, 2014. 